\title{
Surgical Outcome of Coronary Artery Bypass Graft in Patients with Previous Coronary Stenting
}

Gamil Elhusseiny Elhusseiny ${ }^{1}$ MD, Refaie Medhat Ahmad ${ }^{1}$ MD, EL-Sokkary Ismail Nasr ${ }^{1}$ MD, Mohamed Alaa Elsayed Gadelkarem Ahmed ${ }^{1, *}$ MSc

* Corresponding Author:

Mohamed Alaa Elsayed

Gadelkarem Ahmed

alaashandwely85@yahoo.com

\section{Received for publication}

January 21, 2020; accepted

January 30,2020; Published

online February 16, 2020.

Copyright 2020 The Authors published by Al-Azhar

University, Faculty of

Medicine, Cairo, Egypt. All

rights reserved. This an open-

access article distributed under

the legal terms, where it is

permissible to download and

share the work provided it is

properly cited. The work

cannot be changed in any way

or used commercially.

doi:10.21608/aimj.2020.22403. 1078

${ }^{1}$ Cardiothoracic Surgery

Department Faculty of

Medicine, Al-Azhar University,

Cairo Egypt.

\begin{abstract}
Background: With the advancement of percutaneous coronary interventions, patients are presenting to coronary artery bypass grafting (CABG) older, with several co-morbidities and with prior coronary stenting. The outcome of surgery after stenting continues to be debated. We evaluated the surgical outcome of coronary artery bypass grafting in patients with previous coronary stenting.

Material and Methods: This prospective cohort study included 50 patients with previous coronary stent who underwent CABG between February 2016 and June 2017. Thirty-eight patients were males (76\%), and the mean age was $57.66 \pm 8.81$ years. The mean ejection fraction was $41.43 \pm 9.25 \%$. Forty-six patients $(92 \%)$ had previous one stent, and 4 patients $(8 \%)$ had 2 stents.

Results: Nineteen patients had in-stent restenosis (38\%), and 31 patients had new lesions $(62 \%)$. Seven patients had lesions distal to the site of the stent $(14 \%)$. The mean cardiopulmonary bypass time was $102.66 \pm 25.34$ minutes. Two patients needed an intraoperative intra-aortic pump and four in the ICU. Five patients $(10 \%)$ developed acute myocardial infarction. Operative mortality occurred in 4 patients $(8 \%)$; one patient (2\%) had an acute renal failure. Ejection fraction at 6 months postdischarge showed an increase compared to the preoperative value (41.43 $\pm 9.25 \%$ - $44.78 \pm 6.99 \%, \quad \mathrm{P}=0.013)$. Mortality occurred more frequently in patients with IABP and in patients who had MI and renal failure. Mortality was not associated with in-stent stenosis.

Conclusions: Coronary artery bypass grafting in patients with prior coronary stenting could be associated with increased morbidity and mortality. Proper management of coronary artery disease is essential to decrease the risk of future intervention.
\end{abstract}

Keywords: Coronary Artery Bypass Graft; Previous Coronary Stenting; in-stent stenosis.

\section{INTRODUCTION}

Patients presenting to coronary artery bypass grafting (CABG) became older and had multiple comorbidities, which could be attributed to the advancement of percutaneous coronary interventions (PCI). ${ }^{1}$ Many patients may be managed with coronary stenting and present to surgery at a later stage with in-stent restenosis or progression of the native coronary disease. ${ }^{2}$

The impact of previous coronary stenting on the outcome after CABG is still debated. ${ }^{3,4}$ Patients with coronary stenting are prone to stent occlusion before surgery because of the discontinuation of antiplatelets and the use of coagulants during surgery .

The expanding indications for stenting had affected the practice of coronary revascularization. Many patients are still referred for surgery due to the occurrence of stent restenosis, which occurs with an average frequency of $20-30 \% .^{5}$
Authorship: All authors have a substantial contributions to the article.

Disclosure: The authors have no financial interest to declare in relation to the content of this article. The Article Processing Charge was paid for by the authors.

There is a paucity of the studies on the effect of prior coronary stenting on the outcomes of CABG. The aim of the study was to evaluate the surgical outcome of coronary artery bypass graft in patients with previous coronary stenting.

\section{PATIENTS AND METHODS}

\section{Design and patients:}

This is a prospective cohort study conducted between February 2016 and June 2017. Fifty patients with previous coronary stents who underwent $\mathrm{CABG}$ are included in this study. We excluded patients with concomitant surgical procedure, emergence, and re- 
operative surgery and patients with severe end-organ dysfunction and with ejection fraction less than $30 \%$.

\section{Ethical consideration:}

The local Ethical Committee approved the study, and the patients consent was obtained prior to enrollment

\section{Method and data collection:}

All patients had routine preoperative laboratory investigations, 12-lead ECG, trans-thoracic echocardiography, and cardiac catheterization. The carotid duplex was performed in patients with a left main disease, history of stroke or transient ischemic attack or in patients with audible carotid bruit .

All patients had surgical intervention under general anesthesia with endotracheal intubation. The surgical approach was via median sternotomy, the pericardium was opened,and theinternal thoracic artery (ITA) was harvested. All patients had aortic and right atrial cannulation with a two-stage venous cannula. Antegrade cardioplegia was used in all patients. In some patients with in-stent stenosis, the stent was opened, and a patch was done to the left anterior descending artery or other native coronaries. The reversal of heparin action was achieved with protamine sulfate at a ratio of $1 \mathrm{mg}$ for each $100 \mathrm{IU}$ heparin. After obtaining medical and surgical hemostasis, the sternum was closed, and the patient was transported mechanically ventilated to the intensive care unit (ICU). We reported the cardiopulmonary bypass and ischemic times, number of grafts, and the need for mechanical support.

Postoperative data included the duration of mechanical ventilation, the use of intra-aortic balloon pump (IABP), postoperative bleeding, arrhythmias, organ dysfunction, and length of ICU stay.Postoperative echocardiography was done before discharge and after six months.

\section{Statistical analysis :}

Recorded data were analyzed using the statistical package for social sciences, version 20.0 (SPSS Inc., Chicago, Illinois, USA). Quantitative data were expressed as mean \pm standard deviation (SD). Qualitative data were expressed as frequency and percentage. Unpaired-samples t-test was used when comparing between two independent means. The paired sample t-test was used when comparing two related means. The Chi-square test was used to compare two proportions. The confidence interval was set to $95 \%$, and the margin of error accepted was set to $5 \%$.

\section{RESULTS}

\section{Preoperative data:}

Thirty-eight patients were males $(76 \%)$, and the mean age was $57.66 \pm 8.81$ years. Echocardiography was routinely performed preoperatively to assess the left ventricular function, valves, pulmonary artery pressure. The EF ranged from 30-50, with a mean of $41.43 \pm 9.25 \%$
Forty-six patients (92\%) had previous one stent, and 4 patients $(8 \%)$ had 2 stents in different coronary arteries. Nineteen patients had in-stent restenosis (ISR) (38\%), and 31 patients had new lesions (62\%). Seven patients had lesions distal to the site of the stent (14\%), and 24 patients had lesions not related to the location of the stent (48\%).

\section{Operative data:}

The mean cardiopulmonary bypass time was $102.66 \pm 25.34$ minutes. (Table 1) In all patients, pedicled LIMA was used for anastomosis to LAD, long saphenous vein for other targets.

\section{Postoperative data:}

All patients required postoperative mechanical ventilation, and no patient was extubated in the operating theatre. Twenty-five cases needed postoperative inotropic support. Two patients required an intraoperative intra-aortic pump (4\%), and four cases had IABP in ICU (8\%).

We had 5 patients (10\%) who developed acute myocardial infarction; three cases $(6 \%)$ were treated with nitroglycerine, morphine, oxygen, and increased dosage of inotropes until their condition was stabilized. The other two patients were unstable even after adjustment of inotropes, and IABP was used

Operative mortality occurred in 4 patients $(8 \%)$; one patient $(2 \%)$ had acute renal failure not responding to treatment or dialysis, and the other 3 patients $(6 \%)$ had ventricular arrhythmias.

\section{Echocardiography:}

A comparison of the echocardiographic study preoperative andpre-discharge revealed that patients had a decrease in their ejection fraction from $41.43 \pm 9.25 \%$ to $\quad 36.52 \pm 8.29 \% ; \quad \mathrm{P}=0.002$. Echocardiographic study 6 months post-discharge showed that patients had an increase in their ejection fraction to $44.78 \pm 6.99 \%, \mathrm{P}=0.013$.

\section{Mortality:}

There was no significant difference in demographic data between survivors and non-survivors. (Table 2) Mortality occurred more frequently in patients with IABP and in patients who had MI and renal failure. (Table 3) Mortality was not associated with in-stent stenosis. (Table 4)

\begin{tabular}{|l|l|}
\hline Operative data & Total $(\mathbf{n = 5 0})$ \\
\hline $\begin{array}{l}\text { Cardiopulmonary bypass } \\
\text { time }\end{array}$ & $40-160$ \\
\hline $\begin{array}{l}\text { Aortic cross clamp time } \\
(\text { min) }\end{array}$ & {$[102.66 \pm 25.34]$} \\
\hline
\end{tabular}

Table 1: Cardiopulmonary bypass time and aortic cross-clamp time (minutes) presented as range and (mean and standard deviation) 


\begin{tabular}{|c|c|c|c|}
\hline & Survivor $(\mathrm{n}=46)$ & Non-survivor $(\mathrm{n}=4)$ & $\mathrm{P}$ \\
\hline Male & $37(80.4 \%)$ & $1(25 \%)$ & 0.013 \\
\hline Age & $19(41.3 \%)$ & $1(25 \%)$ & 0.523 \\
$\leq 55$ years & $27(59.7 \%)$ & $3(75 \%)$ & \\
> 55 years & $3(6.5 \%)$ & $0(0.0 \%)$ & 0.001 \\
\hline Dyspnea Status & $39(84.8 \%)$ & $1(25 \%)$ & \\
NYHA II & $4(8.7 \%)$ & $3(75 \%)$ & 0.089 \\
NYHA III & $26(56.6 \%)$ & $4(100 \%)$ & 0.307 \\
NYHA IV & $12(26 \%)$ & $2(50 \%)$ & 0.118 \\
\hline Diabetes & $28(60.9 \%)$ & $4(100 \%)$ & 0.587 \\
\hline Hypercholesterolemia & $9(19.6 \%)$ & 0 & 0.99 \\
\hline Hypertension & $23(50 \%)$ & $2(50 \%)$ & \\
\hline Smokers & & & \\
\hline Inotropes & &
\end{tabular}

Table 2: The characteristics of the survivors and non-survivors. Continuous variables are presented as mean and standard deviation and categorical variables as number and percent.

\begin{tabular}{|l|l|l|l|}
\hline & Survivor $(\mathrm{n}=46)$ & Non-survivor $(\mathrm{n}=4)$ & $\mathrm{P}$ \\
\hline Inotropes & $23(50 \%)$ & $2(50 \%)$ & 0.99 \\
\hline Intra-aortic balloon & $4(8.7 \%)$ & $2(50 \%)$ & 0.015 \\
\hline Arrhythmia & $31(67.4 \%)$ & $4(100 \%)$ & 0.171 \\
\hline Bleeding & $9(19.6)$ & $1(25 \%)$ & 0.794 \\
\hline Renal impairment & $2(4.4 \%)$ & $2(50 \%)$ & 0.001 \\
\hline Wound infection & $8(17.4 \%)$ & $1(25 \%)$ & 0.704 \\
\hline Myocardial infarction & $1(2.1 \%)$ & $4(100 \%)$ & 0.001 \\
\hline
\end{tabular}

Table 3: Relation between mortality and complications (Data are presented as number and percent)

\begin{tabular}{|l|l|c|c|}
\hline & Survivor $(\mathrm{n}=46)$ & Non-survivor $(\mathrm{n}=4)$ & $\mathrm{P}$ \\
\hline ISR & $16(34.78 \%)$ & $3(75 \%)$ & \multirow{2}{*}{0.013} \\
\cline { 1 - 3 } New lesion & $30(65.2 \%)$ & $1(25 \%)$ & \\
\hline
\end{tabular}

Table 4: Comparison between survivors and non-survivors according to the lesion of the study group. (ISR: instent restenosis)

\section{DISCUSSION}

Collaborative work of the heart team is essential for the successful management of patients with coronary artery disease. Patients are now presenting to CABG with multiple comorbidities, and many patients had previous coronary stenting. Management of these patients may be challenging.

In our study, 30 patients (60\%) were diabetics, which is higher than what was reported in other studies. ${ }^{9}$ The high prevalence of diabetes in our patients reflects the practice of PCI in our region since most patients prefer to have a PCI even if it is against the recommendations. Additionally, heart surgery centers are not evenly distributed in our country, and many patients are referred to us from remote areas where surgery is not available .
Hypertension was diagnosed in $64 \%$ of our patients, and the prevalence of hypertension varies in different studies, which could be attributed to the various patients' characteristics. ${ }^{9,10}$

Echocardiography was routinely performed preoperatively to assess left ventricle function, valves, and pulmonary artery systolic pressure. The EF improved significantly after 6 months of surgery in our patients, similar to what was reported in other series. ${ }^{11-14}$ Restoration of the blood flow to the viable myocardium is the main contributor to the improved ejection fraction after $\mathrm{CABG}$.

In our study, the cardiopulmonary bypass time was $102.66 \pm 25.34$ minutes, and aortic cross-clamp time was $61.82 \pm 20.89 \mathrm{~min}$. A longer time was consumed in our patients compared to other series, ${ }^{14-15}$ which 
could be attributed to the more dissection, severe distal coronary arteries disease, and the use of coronary artery patch.

Inotropic support was used in 25 cases $(50 \%) ; 23$ of them were used intraoperatively due to EF lower than $40 \%$, while in the other 2 cases $(4 \%)$, inotropes were added in the ICU. The inotropic use in our study was higher compared to other series, ${ }^{13,14}$ which may be related to more extended bypass and ischemic times. Similarly, the use of IABP is different among studies that were related mainly to preoperative patients' hemodynamic status and the extent of the coronary lesions. ${ }^{13,14}$

The incidence of MI was higher in our study. In our opinion, the "more-distal" implantation of the grafted conduit was responsible for increasing the risk of postoperative MI following $\mathrm{CABG}$, and patching of LAD may be a contributor .

Mortality was $8 \%$ in our study, which was similar to many series such as Luiz and associates who had 9.3\% mortality ${ }^{15}$, Yu-Ting, and coworkers who had $8.2 \%$ mortality ${ }^{13}$ and Sandra and coworkers who had $9 \%$ mortality. ${ }^{14}$ Our patients had $38 \%$ ISR, which is in agreement with the study carried out by Sohrab and collaborators, ${ }^{12}$ who had $28 \%$ ISR. We did not find an association between postoperative mortality and ISR.

\section{Study limitations:}

The major limitation of the study is the limited number of patients and the single-center experience. We recommend the conduction of a multi-center study to thoroughly evaluate the effect of prior coronary stenting on the outcomes after CABG.

\section{CONCLUSION}

Coronary artery bypass grafting in patients with prior coronary stenting could be associated with increased morbidity and mortality. Proper management of coronary artery disease is essential to decrease the risk of future intervention.

\section{REFERENCES}

1. Lancet A. Coronary angioplasty versus medical therapy for angina: the second Randomised Intervention Treatment of Angina (RITA-2) trial. RITA-2 trial participants. 1997;350:461- 468.

2. Paviotti C, Liprandi MI and Palacios IF. Metaanalysis of 9 RCT's of PTCA vs. CABG Significantly INFERIOR at 5 yrs and 8 yrs JACC 2003.41:1293.

3. Lancet A. Coronary artery bypass surgery versus percutaneous coronary intervention with stent implantation in patients with multivessel coronary artery disease (the Stent or Surgery trial): a randomised controlled trial. 2002;3 60:965-970.

4. Judith MD and Luc Noyez FWA. Risk of coronary surgery for hospital and early morbidity and mortality after initially successful $\begin{array}{lll}\text { percutaneous } \quad \text { intervention. } & \text { Interact } \\ \text { CardioVascThoracSurg 2005;4:96-100. } & \end{array}$

5. Georgios S, Marie-Angèle M, Arie PK, MarieClaude M, Antonio C et al. The SYNTAX Score: an angiographic tool grading the complexity of coronary artery disease. Department of Interventional Cardiology, Erasmus Medical Center, Thoraxcenter Rotterdam. EuroInterv. 2005; 1:219-227.

6. Constance KH, Sean O, Fred HE, et al. Trends in Emergency Coronary Artery Bypass Grafting After Percutaneous Coronary Intervention, 19942003 Ann ThoracSurg 2006;81:1658-1665.

7. Vito M, Di Tommaso L, De Amicis V, et al. Previous percutaneous coronary interventions increase mortality and morbidity after coronary surgery. The Annals of Thoracic Surgery. 2012; 93(6):1956-62.

8. Gaurav SM, LaPar DJ, Bhamidipati CM, et al. Previous percutaneous coronary intervention increases morbidity after coronary artery bypass grafting. Surgery. 2012 Jul 1;152(1):5-11.

9. Saleh A, Hammoudeh A, Tabbalat R, et al. Incidence and prognosis of stent thrombosis following percutaneous coronary intervention in Middle Eastern patients: The First Jordanian Percutaneous Coronary Intervention Registry (JoPCR1). Annals of Saudi Medicine. 2016; 36 (1):17-22

10. Sohrab N, Anvari S, Abbasi K, et al. Immediate postoperative complications in patients undergoing $\mathrm{CABG}$; investigating the role of prior coronary stenting. Journal of Cardiovascular and Thoracic Research. 2014;6(4):229.

11. Yu-Ting $\mathrm{C}$, Chen SW, Chang $\mathrm{CH}$, et al. Impact of prior coronary stenting on the outcome of subsequent coronary artery bypass grafting. Biomedical Journal. 2017;40(3):178-84.

12. Murat SÇ, Özyalçin S, Özen A, et al. Does really previous stenting affect graft patency following CABG? A 5-year follow-up. Heart and Vessels. 2016; 31(4):457-64.

13. Ewa GZ, Żurek P, Kaźmierski M, et al. Coronary artery bypass grafting in patients with relatively recent previous stent implantation: three years follow-up results. Cardiology Journal. 2009;16 (4):312-6.

14. Sandra E, Mair H, Boulesteix AL, et al. Midterm outcomes of patients with PCI prior to CABG in comparison to patients with primary CABG. Vascular Health and Risk Management. 2010; 6:495.

15. Lisbon LA, Mejía OA, Dallan LA, et al. Intervenção Coronariana Percutânea prévia comofator de risco para Revascularização Miocárdica. Arq Bras Cardiol. 2012;99 (1):58695. 